\title{
Orientações Pedagógicas: Contribuições para atuação de psicólogos escolares no Distrito Federal
}

\author{
Liliene Alves Veloso da Silva \\ Claisy Maria Marinho-Araujo \\ Universidade de Brasília
}

Resumo: A literatura aponta mudanças nas concepções e práticas dos psicólogos escolares na direção de uma perspectiva de atuação crítica. O Distrito Federal se destaca nacionalmente pelas políticas públicas voltadas para inserção do psicólogo escolar na Secretaria de Estado de Educação (SEDF). O presente artigo tem como objetivo verificar os avanços apresentados historicamente nas Orientações Pedagógicas (OP), documentos oficiais das SEDF que estabelecem as diretrizes para a atuação da Psicologia Escolar. Foram examinadas as publicações referentes aos anos de 1992, 1994, 2006 e 2010. Os resultados evidenciaram a contribuição dessas normatizações para a ressignificação de concepções e mudanças nas práticas do psicólogo escolar.

Palavras-chave: Psicologia Escolar. Orientação Pedagógica. Psicólogo escolar 


\section{Pedagogical guidelines: Contributions to acting school psychologists in the Federal District}

The literature points to changes in concepts and practices of school psychologists into a perspective of critical performance. The Education State Secretariat of Federal District (SEDF) distinguishes itself in the national context for implementing public policies aimed at providing the inclusion of the psychologists in the school. This research aims to signal to the improvements in the school psychology guidelines of the school psychology in the SEDF. With that in mind were assessed the publications of 1992, 1994, 2006 and 2010. Results showed the contributions of pedagogic guidelines for the redefinition of concepts and changes in school psychologists practices.

Keywords: School Psychology. Educational Guidance. School Psychologist.

\section{Directrices pedagógicas: Contribuciones para actuar psicólogos escolares en el Distrito Federal}

La literatura sugiere cambios en las concepciones y prácticas de los psicólogos escolares para una perspectiva de rendimiento crítico. El Departamento de Estado y el de Educación del Distrito Federal (SEDF) es a nivel nacional por las políticas públicas orientadas a la inclusión del psicólogo en el escuela. Este artículo tiene como objetivo destacar los avances en la Directrices pedagógicas, que establecen las directrices de Psicología Escolar en SEDF. Para ello se examinaron las publicaciones de los años 1992, 1994, 2006 y 2010. Los resultados mostraron la contribución de estas normas en las prácticas psicólogo escolar.

Palabras clave: Psicología Escolar. Orientación Educativa. Psicólogo escolar 


\section{Des orientations Pédagogiques: Des Contributions pour l'action despsychologues escolaires à Distrito Federal.}

La litterature montre des changements dans les conceptions et les pratiques des psychologues scolaires dans la direction d'une perspective d'action critique. Le Distrito Federal se détache au niveau national par ses politiques publiques tournées vers I 'insertion du psychologue scolaire dans le Secrétariat d'État d'Éducation du Distrito Federal (SEDF). Cet article a le but de vérifier les avancements présentés historiquement dans les Orientations Pedagógiques (OP), des documentes officiels des SEDF qui établissent les directives pour I'action de la Psychologie Scolaire. Les publications référées aux années 1991, 1994, 2006 e 2010 ont été examinées. Les résultats ont mis em évidence la contribution de ces standartisations pour une nouvelle signification des conceptions et des changements dans les pratiques $d u$ psychologue scolaire.

Mots-clés: La Psychologie Scolaire; L'Orientation Pédagogique; Psychologuescolaire 


\section{Introdução}

Os processos de desenvolvimento humano e de aprendizagem foram estudados pela Psicologia, em seus primórdios, por diferentes abordagens teóricas e epistemológicas que nem sempre consideravam questões institucionais, políticas e sociais presentes no contexto escolar. A Psicologia, como disciplina científica, no final do século XIX enfatizava o aparato biológico e a relação estímulo-resposta para explicar seus princípios, que omitiam a participação do contexto social no desenvolvimento de funções psicológicas mais complexas (Vygotsky, 1926/2004). $\mathrm{Na}$ Psicologia Escolar, os conceitos e teorias formuladas sobre os aspectos evolutivos, cognitivos, emocionais e sociais dos processos de desenvolvimento e aprendizagem contribuíram para os avanços dessa área do conhecimento.

No Brasil, a relação da Psicologia com a Educação foi orientada por concepções teóricas e ideológicas que explicavam as diferenças individuais a partir de aspectos orgânicos ou psicológicos e a utilização descontextualizada de instrumentos psicométricos (Patto, 1984; Correia \& Campos, 2004). O conhecimento psicológico contribuía para mascarar as desigualdades sociais promovendo práticas classificatórias e excludentes (Antunes, 2008). As condições sociais que facilitavam ou impediam o desenvolvimento do sujeito eram ocultadas em discursos abstratos e ideológicos que naturalizavam o fenômeno psicológico presente em uma atuação curativa e terapêutica do psicólogo escolar (Antunes, 2008; Bock, 1999; Martín Baró, 1996; 2011; Martinez, 2009).

Com a ampliação do sistema educacional brasileiro, em 1960, a Psicologia constituiuse como uma prática profissional sistemática nas escolas. A atuação do psicólogo escolar centrava-se em diagnósticos e atendimentos individualizados aos alunos com histórico de fracasso escolar (Cavalcante \& Aquino, 2013; Correia \& Campos, 2004; Guzzo\&Mezzalira, 2011; Marinho-Araujo\& Almeida, 2005; Neves \& Almeida, 2003; Patto, 1990; Petroni, 2013). As dificuldades de aprendizagem eram atribuídas às questões biológicas ou ambientais, localizadas no estudante ou na família, que deveriam ser tratadas para promover a adaptação ao texto escolar (Marinho-Araujo\& Almeida, 2005; Marinho-Araujo, 2010, 2014; Patto, 1981, 1984, 1990; Petroni, 2013).

A partir da década de 1980, a Psicologia, como ciência, promoveu reflexões teóricoconceituais que procuravam redefinir a atuação do psicólogo a partir de perspectivas políticas, éticas e sociais mais abrangentes. Vários estudiosos passaram a criticar práticas psicológicas individualizantes e patologizantes, além de defender uma identidade para o psicólogo escolar comprometida com o desenvolvimento dos atores educativos e com as transformações sociais (Bock, 1999; Guzzo\&Mezzalira, 2011; Martín-Baró, 1996, 2011; Marinho-Araujo, 2010, 2014). Na escola pública, 
essa presença ideológica era evidenciada em práticas de diagnóstico e classificação que excluíam os estudantes por questões socioeconômicas, formas singulares de ser, pensar, agir, sentir ou por apresentarem dificuldades de aprendizagem, principalmente nas classes populares, restringindo o acesso dessas crianças ao conhecimento (Guzzo, 2007; Guzzo\&Mezzalira, 2011; Marinho-Araujo, 2010, 2014; Patto, 1981, 1990).

Estudos como os de Araújo, 2003; Guzzo, 2007; Marinho-Araújo e Almeida, 2005; Martinéz, 2009; Neves, 2003 têm subsidiado pesquisas e alimentado discussões acerca das concepções e práticas em Psicologia Escolar, incorporando a compreensão de aspectos sociais, históricos, culturais e relacionais presentes no processo educativo nas propostas uma atuação institucional que envolva todos os atores educativos. As mudanças na atuação dos psicólogos no contexto educativo na rede pública de ensino do Distrito Federal têm sido graduais e encontram-se na transição de uma atuação com foco individualizante para uma atuação institucional.

\section{Psicologia escolar na Secretaria de Estado de Educação do Distrito Federal.}

A Secretaria de Estado de Educação do Distrito Federal (SEDF) é responsável pela educação na rede pública e particular e está subdividida em 14 Coordenações Regionais de Ensino (CRE). As CRE são responsáveis pedagógica e administrativamente pelas 680 instituições de ensino públicas do DF (GDF, 2014). A Psicologia Escolar está presente, na SEDF, desde 1968, de forma institucionalizada promovendo atendimento aos estudantes. Nessas últimas quatro décadas, houve instabilidades e mudanças na organização e estruturação desse atendimento e nas Orientações Pedagógicas (OP) que estabelecem as diretrizes técnico-pedagógicas para atuação do psicólogo escolar.

Atualmente a Psicologia Escolar na SEDF é denominada Equipe Especializada de Apoio à Aprendizagem (EEAA), que é definida como um serviço de apoio técnico-pedagógico, de caráter multidisciplinar, prestado por profissionais com formação e devidamente habilitados nas áreas de pedagogia e psicologia (GDF/SEDF, 2010). A gestão das EEAA é realizada pela Subsecretaria de Educação Básica (SUBEB), que coordena as políticas públicas educacionais do Governo do Distrito Federal. A SUBEB conta com várias diretorias, dentre elas, a Coordenação de Ensino Fundamental (COENF), onde se encontra o Núcleo das Equipes Especializadas de Apoio à Aprendizagem (NUEEAA), responsável pela coordenação e supervisão da atuação dos profissionais que compõem a EEAA e pela capacitação e implantação da OP/2010 (GDF/SEDF, 2010), que é a diretriz vigente. Existe, ainda, uma coordenação intermediária localizada 
em cada CRE do DF, que promove a organização e operacionalização do serviço oferecido pela EEAA (GDF/SEDF, 2010) nas regiões administrativas.

Há 47 anos o psicólogo escolar participa de equipes multidisciplinares no âmbito da SEDF, atuando com pedagogos (Barbosa, 2008; GDF, 2010;Marinho-Araujo, Neves, Penna-Moreira \& Barbosa, 2011; Penna-Moreira, 2007). Com a criação, em 1971, do Centro de Orientação Médico-Psicopedagógico (COMPP), órgão da Secretaria de Saúde do Distrito Federal (SESDF) que prestava atendimento multi e interdisciplinar em Saúde Mental às crianças e adolescentes do DF e entorno (GDF/SES, 2015), uma equipe multidisciplinar, formada por médicos, psiquiatras, fonoaudiólogos, psicólogos e pedagogos que passou a atender os alunos com necessidades especiais mediante convênio firmado entre a SESDF e a SEDF (Marinho-Araujo, et al., 2011). Após três anos de funcionamento, o número elevado de estudantes encaminhados inviabilizou o atendimento no COMPP, razão pela qual foi criada, em 1974, a Equipe de Diagnóstico/ Avaliação Psicopedagógica do Ensino Especial, instalada no Centro de Ensino Especial $\mathrm{n}^{\circ} 01$ de Brasília. O COMPP ficou responsável somente pelo atendimento às queixas de dificuldades de aprendizagem (Marinho-Araujoet al., 2011).

A Equipe de Diagnóstico/Avaliação Psicopedagógica do Ensino Especial centravase na "avaliação e atendimento dos portadores de necessidades especiais de toda a rede pública de ensino do DF" (Marinho-Araujoet al., 2011, p. 58). A atuação do psicólogo escolar acompanhou as discussões nacionais voltadas para as concepções higienistas, biologizantes e medicalizantes que orientavam práticas individualizantes como a "realização de diagnóstico diferencial em crianças com história de fracasso escolar ou portadoras de necessidades especiais" (Marinho-Araujo, et al., 2011, p. 57). De acordo com Neves (2001), a criação dessa equipe fazia parte da política pública educacional brasileira que, desde a década de 1960, vislumbrava oferecer à população atendimentos compensatórios aos deficit culturais, fisiológicos e afetivos com vistas à superação do fracasso escolar.

Para Marinho-Araujoet al. (2011), a atuação da Equipe de Diagnóstico/Avaliação Psicopedagógica do Ensino Especial evidenciou que os estudantes encaminhados para avaliação não apresentavam deficiências, mas dificuldades de aprendizagem, o que motivou, em 1980, a reformulação desse atendimento pela Divisão de Apoio Escolar (DAE), atualmente denominada Diretoria de Ensino Especial (DEE). Em 1987, foram criadas as Equipes de Atendimento Psicopedagógico para atender os estudantes com dificuldades de aprendizagem do ensino regular (FEDF, 1992). Dessa forma, passaram a existir duas equipes multidisciplinares distintas: uma voltada para o ensino especial e outra que oferecia atendimento especializado aos estudantes do ensino regular.

A criação das Equipes de Atendimento Psicopedagógico promoveu a revisão 
dos pressupostos teóricos que consideravam os estudantes com dificuldades de aprendizagem, portadores de deficiências (FEDF, 1992,1994; Marinho-Araújo et al., 2011; Neves, 2001). No entanto, as concepções de desenvolvimento e aprendizagem que orientavam as práticas dos psicólogos escolares permaneceram responsabilizando o aluno pelo fracasso escolar, seja por questões orgânicas, problemas psicológicos ou condição social, cultural e econômicas (Collares\& Moysés, 1996; Cavalcante \& Aquino, 2013; Marinho-Araujo, 2010; Patto, 1981, 1990).

Pesquisas realizadas com os psicólogos escolares da SEDF propunham a superação de práticas que culpabilizavam o aluno pelo fracasso e a construção de identidade profissional para o psicólogo escolar (Araújo, 2003; Barbosa, 2008; Marinho-Araujo\& Almeida, 2003; Neves 1994, 2001; Penna-Moreira, 2007; Senna \& Almeida, 2005). Sob a influência de Araujo (2003) e Neves (2001), a SEDF promoveu uma reestruturação, com a fusão das equipes que atendiam o ensino regular e o ensino especial, criando as Equipes de Atendimento e Apoio à Aprendizagem (EAAA).

A EAAA favoreceu a compreensão da escola como espaço subjetivo de desenvolvimento, bem como a importância da participação dos professores, pais e gestores como copartícipes em ações que favoreçam o processo educacional (Marinho-Araujo, 2014; Neves, 2011). Na atuação do psicólogo escolar, houve a ampliação de práticas tradicionalmente individualizantes e remediativas para práticas coletivas e institucionais, envolvendo todo o contexto escolar, como ações de apoio e intervenção junto aos alunos, professores, família e gestores.

Em 2008, as contribuições da Psicologia Escolar para a melhoria da educação pública no âmbito da SEDF foram questionadas e a permanência das EAAA ameaçada por gestores do governo local. Diante da possibilidade de dissolução do serviço, os profissionais de diversas Coordenações Regionais de Ensino do DF se mobilizaram e organizaram uma comissão nomeada Pró-EAAA para representar os interesses da Psicologia Escolar no âmbito da SEDF (Marinho-Araujo et al., 2011). Essa mobilização mostrou que o psicólogo escolar deve exercer um papel político e social, tanto na escola, onde a sua ação deve influenciar mudanças por meio da conscientização dos sujeitos (Guzzo, 2007), quanto na participação da elaboração e implementação de políticas públicas educacionais (Martínez, 2010).

As manifestações a favor da permanência da Psicologia Escolar na SEDF contaram com o apoio de entidades representativas como o Sindicato dos Professores do Distrito Federal (Sinpro-DF), o Conselho Regional de Psicologia (CRP) da $1^{\text {a }}$ Região e grupos organizados de pais, professores, diretores e comunidade. A parceria dos profissionais das EAAA com o Laboratório de Psicologia Escolar do Instituto de Psicologia da Universidade de Brasília, por meio do Projeto de Extensão e Ação Contínua (PEAC), 
que, desde 1995, oferece aperfeiçoamento em serviço aos psicólogos escolares que atuam na SEDF, também contribuiu para o enfrentamento da crise, por meio da oferta de assessoria técnica e científica à Comissão Pró-EAAA na elaboração de documentos, relatórios e divulgação da produção acadêmica acerca da Psicologia Escolar no âmbito da SEDF (Marinho-Araújo, et a., 2011; GDF/SEDF, 2010). Essas articulações resultaram em conquistas como a publicação da Portaria $n^{\circ} 254,12$ de dezembro de 2008, publicada no Diário Oficial do Distrito Federal $n^{\circ} 248$, de 14 de dezembro de 2008, que regulamentou as EAAA, denominando-as Equipes Especializadas de Apoio à Aprendizagem (EEAA)(Marinho-Araújo, et a., 2011, p. 64).

O presente artigo relata o estudo que procurou evidenciar concepções e práticas em Psicologia Escolar, bem como as contribuições das Orientações Pedagógicas para a atuação do psicólogo escolar, por meio de análise documental que faz parte da pesquisa intitulada História, diretrizes, avanços e desafios na Psicologia Escolar no Distrito Federal: as vozes dos psicólogos escolares das Equipes Especializadas de Apoio à Aprendizagem de Ceilândia. A pesquisa foi submetida ao Comitê de Ética que acompanha a participação de seres humanos em pesquisa, de acordo com a Resolução $n^{\circ}$ 466/12 (CNS, 2012) e aprovada conforme o parecer 860.102. Esse estudo

apresenta relevância social ao verificar as possibilidades de utilização da Orientação Pedagógica como um recurso para a uma atuação consciente e transformadora do psicólogo escolar.

\section{Método}

Os objetivos desse estudo foram investigar os avanços da Psicologia Escolar na SEDF e a influência das OP na atuação do psicólogo escolar. Os documentos examinados foram as primeiras Orientações Pedagógicas (OP) da Psicologia Escolar na SEDF: OP $n^{\circ} 20$ (FEDF,1992) e OP $n^{\circ} 22$ (FEDF,1992,1994), publicadas 18 anos após a criação da primeira Equipe de Diagnóstico/Avaliação Psicopedagógica do ensino especial e cinco anos após a instituição das Equipes de Atendimento Psicopedagógico para todo o sistema público de ensino (Marinho-Araújo et al., 2011). Além dessas também foi objeto de estudo a OP/2006 (GDF/SEDF, 2006) e a OP/2010 (GDF/SEDF, 2010).

No procedimento de análise das informações, optou-se pela construção de categorias, que, na perspectiva qualitativa, configuram-se como instrumentos do pensamento que podem expressar não apenas o objeto estudado, mas o contexto históricocultural (Branco \& Madureira, 2001; Rey, 2014). A partir das etapas de análise textual, temática e interpretativa, propostas por Severino (2007) foram identificados os temas 
significativos das Orientações Pedagógicas para compreensão da Psicologia Escolar na SEDF que originaram as seguintes categorias: ano de identificação, composição, público-alvo, objetivos, concepções e atuação do psicólogo escolar. As discussões foram subsidiadas pelos pressupostos da Psicologia Escolar contemporânea.

\section{Resultados e Discussão}

As informações construídas a partir da análise documental das Orientações Pedagógicas OP n 20 (FEDF,1992), OP nº 22 (FEDF,1992,1994), OP/2006 (GDF/ SEDF, 2006) e a OP/2010 (GDF/SEDF, 2010) serão apresentadas em consonância com os objetivos propostos. Dessa forma espera-se verificar as contribuições dessas diretrizes para a atuação do psicólogo escolar na SEDF. A Tabela 1 apresenta a definição das categorias resultantes do processo de análise documental das OP.

Tabela 1- Definição das categorias de análise

\section{Categorias Definições}

1. Identificação

2. Composição

3. Público alvo

4. Objetivos

5. Concepção

6. Atuação em Psicologia Escolar
Anuncia a nomenclatura e denominação dos serviços multidisciplinares que incluem a Psicologia Escolar.

Refere-se aos profissionais que atuam como psicologia escolar.

Aponta o público ao qual a Psicologia Escolar se responsabiliza na sua atuação.

Apresenta os propósitos que orientam as ações da Psicologia Escolar.

Identifica os pressupostos teóricos que subsidiam as ações da Psicologia Escolar

Relaciona as ações e atividades a serem realizadas pelo psicólogo escolar.

Na primeira categoria, Identificação, a Psicologia Escolar estava inserida, respectivamente, em cada OP analisada, nas Equipes de Atendimento Psicopedagógico; Equipes de Atendimento Diagnóstico e Avaliação Psicopedagógica; Equipes de Atendimento/Apoio à Aprendizagem (EAAA). Atualmente, o psicólogo escolar trabalha nas Equipes Especializadas de Apoio à Aprendizagem (EEAA). Percebe-se, 
nas nomenclaturas utilizadas nas OP, uma permanente articulação da Psicologia com a Pedagogia em ações de atendimento, avaliação e apoio ao processo de aprendizagem.

A segunda categoria, Composição, mostrou que a Psicologia Escolar na SEDF apresenta um caráter multidisciplinar, em que o psicólogo e o pedagogo são profissionais permanentes, mas que já contou com a participação de outros profissionais tais como o orientador educacional OP/2006 (GDF/SEDF, 2006). Atualmente as EEAA são compostas por profissionais com formação em Psicologia e Pedagogia (OP/2010;GDF/ SEDF, 2010).

A terceira categoria, Público Alvo, diz respeito a quem se beneficia da Psicologia Escolar na SEDF. Na OP n. 20 (FEDF, 1992) a atuação do psicólogo escolar se destinava aos alunos do ensino fundamental (séries iniciais) matriculados no ensino regular que apresentavam dificuldades de aprendizagem. Esse público foi ampliado na segunda edição desse documento para o então $1^{\circ}$ e o $2^{\circ}$ grau da rede oficial de ensino (FEDF, 1994b). Na OP ${ }^{\circ} .22$ (FEDF, 1994a), o atendimento era destinado apenas aos estudantes com necessidades educacionais especiais (ENEE). A OP/2006 (GDF/SEDF, 2006) ampliou o atendimento à educação infantil bem como aos estudantes com dificuldades de aprendizagem e aos ENEE. A OP/2010 (GDF/SEDF, 2010) estendeu o atendimento para outras modalidades como o ensino fundamental (anos finais), o ensino médio e a educação de jovens e adultos (GDF, 2014).

$\mathrm{Na}$ quarta categoria, Objetivos, as diretrizes propõem: (a) o diagnóstico e atendimento das dificuldades dos estudantes para melhoria do desempenho acadêmico; (b) o atendimento e apoio aos atores do processo educativo; (c) a atuação institucional voltada para o desenvolvimento humano. As OP $n^{\circ} .20$ (FEDF, 1992) e OP $n^{\circ} .22$ (FEDF, 1994a), visavam promover a melhoria no desempenho escolar. A OP/2006 apresentava avanços em relação às normatizações anteriores ao propor ações envolvendo outros contextos e incluindo os atores educativos além do atendimento ao aluno. São objetivos dessa OP:

\begin{abstract}
Apoiar e subsidiar o corpo docente, auxiliando-o a desenvolver estratégias educacionais que respondam às diferentes necessidades dos alunos no contexto escolar e sensibilizar as famílias para maior participação no processo avaliativo/interventivo tornando-as corresponsáveis pelo desenvolvimento e aprendizagem dos alunos (GDF/SEDF, 2006, p.12).
\end{abstract}

Dentre os documentos examinados, a OP/2010 (GDF/SEDF, 2010) é a que mais se aproxima das discussões da Psicologia Escolar crítica contemporânea. Os objetivos dessa diretriz apontam para uma perspectiva de atuação compromissada com 
desenvolvimento humano e a melhoria da Educação a partir da atuação do psicólogo escolar na perspectiva institucional, preventiva e relacional (GDF/SEDF, 2010; Marinho-Araújo, 2010, 2014;Marinho-Araújo \& Almeida, 2005). Nessa perspectiva, a normatização propõe:

Promover a melhoria na qualidade do processo de ensino e aprendizagem, por meio de intervenções avaliativas, preventivas e institucionais; favorecer a ressignificação de concepções de ensino e aprendizagem dos atores da instituição educacional, promovendo a consolidação de uma cultura de sucesso(GDF/SEDF, 2010, p. 91).

Na quinta categoria, Concepção, verificou-se que as OP n 20 (FEDF, 1992, 1994b) e $n^{\circ} 22$ (FEDF,1994a) foram influenciadas pelos estudos do desenvolvimento humano presentes nas décadas de 1970 e 1980, cujos referenciais epistemológicos e abordagens teóricas explicavam as mudanças ocorridas no ser humano ao longo da sua vida a partir de fatores biológicos, psíquicos e sociais. Essas explicações influenciavam a compreensão acerca das dificuldades de aprendizagem: "os problemas de ordem biopsicossociais são traduzidos sob a forma de obstáculos que ocasionam comprometimentos no desenvolvimento da aprendizagem, na integração social ou mesmo impediam a ida do aluno à escola ou permanecia na mesma" (FEDF, 1992, p.05).

O conhecimento psicológico era utilizado pelo psicólogo para confirmar o fracasso escolar de crianças, principalmente de classes menos favorecidas, a partir de critérios biológicos, neurológicos, sociais (Antunes, 2008; Guzzo\&Mezzalira, 2011; MarinhoAraujo, 2010, 2014; Patto, 1981, 1990). Se, por um lado, a escola procurava na área da saúde as causas e soluções de questões cuja gênese era social e política (Collares\& Moysés, 1996; Cavalcante \& Aquino, 2013; Marinho-Araujo, 2010), por outro, responsabilizava a carência cultural pelas dificuldades escolares dos alunos (Patto, 1981, 1990). A OP nº 22 (FEDF, 1994a) evidenciava a importância da identificação das limitações do estudante para promover as adequações necessárias ao seu desenvolvimento e aprendizagem:

A Educação Especial visa oferecer recursos apropriados que assegurem condições favoráveis para o êxito da escolarização e o fomento da integração social dos alunos portadores de necessidades educacionais especiais, por mais acentuadas que sejam as diferenças individuais. Dessa forma torna-se imprescindível, o mais cedo possível, de investigação das características psicopedagógicas de cada aluno, identificando aspectos que interferem na sua capacidade de aprendizagem e de desenvolvimento (FEDF, 1994a, p.05). 
A segunda edição da OP n 20 (FEDF, 1994b), promoveu mudanças na estrutura e funcionamento do serviço de Psicologia Escolar, oferecendo atendimento especializado, realizado por psicólogos das Equipes de Atendimento Psicopedagógico e atendimento preventivo, realizados por psicólogos inseridos no cotidiano escolar, fazendo parte da equipe e atuando junto aos atores educativos (professores, família e alunos) em uma perspectiva institucional (Araújo, 2003). Os profissionais que atuavam na Psicologia Escolar da SEDF atuavam em categorias funcionais distintas: magistério e assistência. Os psicólogos das equipes multiprofissionais eram da carreira magistério, ou seja, professores licenciados em diversas áreas, mas com formação em Psicologia e os profissionais inseridos na escola faziam parte da carreira assistência e eram considerados "especialistas - psicólogos". De acordo com Araújo (2003), embora existisse, à época da OP n 20 (FEDF, 1994b), 150 psicólogos em equipes multidisciplinares da SEDF, pouco mais de 20 profissionais estavam inseridos na escola, atuando preventivamente. Essa diretriz inovou a atuação dos psicólogos escolares ao "defender que problemas como evasão e repetência, fracasso escolar e de ocorrências de aprendizagem poderiam ser minimizados por meio de uma ação preventiva" Araujo (2003, p.157).

No cenário acadêmico local, articulações entre o Laboratório de Psicologia da Universidade de Brasília e Psicologia Escolar nas Equipes de Atendimento da SEDF culminaram na criação, em 1995, do Projeto Permanente de Ação Contínua (PEAC), que visava fortalecer a Psicologia Escolar enquanto área de produção de conhecimento, divulgar produções acadêmicas para os psicólogos da SEDF e oferecer formação teórico-prática em Psicologia. Atualmente, o PEAC se apresenta aos profissionais da SEDF como uma alternativa de "reconstrução da própria história e de tomada de consciência sobre as possibilidades de atuação, fortalecendo a identidade profissional e o aprofundamento teórico-conceitual articulado com as práticas preventivas e institucionais no contexto escolar" (Marinho-Araujo\& Neves, 2007, p. 72). Essa diretriz impactou a Psicologia Escolar da SEDF, tornando-se uma referência no que concerne à formação continuada. A criação do Projeto de Extensão marcou o início de uma sólida parceria entre as professoras do Laboratório de Psicologia Escolar do Instituto de Psicologia da Universidade de Brasília e os psicólogos escolares da SEDF, construindo um espaço de interlocução permanente entre teoria e prática profissional.

Embora a OP $n^{\circ} 22$ (FEDF, 1994a) tenha reconhecido que os estudantes com dificuldades de aprendizagem não eram deficientes, o documento pouco avançou na mudança de concepção acerca das dificuldades de aprendizagem, substituindo o determinismo biológico pelo determinismo psicológico. Segundo Neves (2001), "ocorreu apenas uma troca de explicações de ordem médica para psicológica; no entanto, a questão central permaneceu inalterada, ou seja, a biologização dos problemas escolares e sociais" (p.49). 
Na perspectiva da Psicologia Escolar crítica, as práticas dos psicólogos escolares, baseadas nessas concepções biologizantes e segregadoras, visavam identificar, tratar e promover o ajustamento dos estudantes ao contexto escolar (Facci\& Souza, 2011; Guzzo, 2007; Marinho-Araujo, 2010; Marinho-Araujo\& Almeida, 2005). Deve-se ressaltar que a identificação, a avaliação e o atendimento das dificuldades de aprendizagem são imprescindíveis ao andamento do processo de ensino e aprendizagem; entretanto, devem ser considerados, além do aluno, as questões sociais, políticas, econômicas e interescolares para o enfrentamento das queixas escolares (Marinho-Araujo \& Almeida, 2005; Marinho-Araujo, 2014; Neves, 2011).

A OP/2006 (GDF/SEDF, 2006) apresentou avanços na concepção de avaliação a ser realizada preferencialmente na escola, considerando fatores pedagógicos, intersubjetivos, sociais, familiares, contrapondo-se ao modelo clínico no qual o aluno era retirado do contexto em que a queixa foi produzida e atendido individualmente (Neves, 2001). Essa normatização permitiu a flexibilidade temporal no processo avaliativo, prescindindo de períodos longos e desnecessários de atendimento. A mudança se deu a partir da releitura de práticas individualizantes:

Mediante a atual compreensão das dificuldades de aprendizagem e/ou necessidades educacionais, é consenso, no âmbito educacional, a importância da revisão e atualização de conceitos e práticas avaliativas tradicionais, normativas, padronizadas e classificatórias, ainda vigentes nas nossas instituições educacionais (GDF/SEDF, 2006, p. 13).

A proposta de atuação do psicólogo escolar junto ao professor apresentada nesta diretriz tornou-se uma alternativa à forma tradicional de enfrentamento das queixas escolares, centrada no atendimento individualizante com foco no aluno. As questões escolares deveriam ser analisadas considerando aspectos subjetivos, socioculturais, influências de políticas educacionais e do próprio processo de desenvolvimento e aprendizagem em curso (Neves, 2011).

A OP/2010 (GDF/SEDF, 2010) se destaca na historicidade das OPs analisadas por evidenciar os pressupostos epistemológicos, teóricos e metodológicos que orientam a atuação do psicólogo escolar. O documento apresenta a concepção do "desenvolvimento como um processo histórico, no qual tanto o ambiente das relações sociais quanto o funcionamento orgânico e o aparato biológico dos indivíduos, induzem ao desenvolvimento de funções psicológicas superiores." (GDF/SEEDF, 2010, p. 57).

Essa normatização está fundamentada nos pressupostos da abordagem históricocultural que preconizam a gênese social do desenvolvimento humano, na qual a 
constituição humana não se restringe à condição biológica, mas se transforma qualitativamente mediante a apropriação dos elementos culturais, construídos e historicamente representados pela humanidade, por meio da atividade humana (Vygotsky, 1984/2007). Nessa perspectiva teórica, o aprendizado é considerado fundamental para o desenvolvimento do psiquismo humano, principalmente pela atuação intencional da educação.

O documento destaca a importância do papel da escola no desenvolvimento social, cognitivo, afetivo, cultural de todos os atores educativos por meio das relações constituídas no contexto escolar,enfatizado a complexidade do processo educativo, a multiplicidade de fatores presentes nas questões escolares como a história, a cultura, os fatores econômicos, sociais, filosóficos, sociológicos, antropológicos e psicológicos. Essa diretriz propõe uma releitura de concepções para superação do fracasso e promoção do sucesso escolar, a partir do compromisso ético-politico-social do psicólogo escolar com o desenvolvimento humano e a com transformações sociais (GDF/SEDF, 2010). A diretriz ressalta:

A construção de uma cultura de sucesso escolar está irremediavelmente relacionada à adoção de concepções de desenvolvimento e de aprendizagem que promovam o desapego às estruturas defasadas e cristalizadas que, até então, orientam as práticas e os processos educativos na escola (GDF/SEDF, 2010, p.53).

Na sexta categoria, Atuação em Psicologia Escolar, verificou-se que, nas OP $\mathrm{n}^{\circ} 20$ (FEDF, 1992) e n 22 (FEDF, 1994a), a atuação do psicólogo escolar seguia o modelo clínico-remediativo, por meio de práticas de aconselhamentos, mediação de questões emocionais e conflitos interpessoais visando o ajustamento dos estudantes ao contexto escolar. Ao psicólogo escolar cabia fazer o "atendimento psicológico das dificuldades de adaptação escolar do aluno ou problemas de comportamento oriundos de fatores socioeconômicos, culturais ou emocionais e/ou problemas psicomotores, que estivessem interferindo no processo de ensino-aprendizagem." (GDF/FEDF, 1992, pp. 11-12). As queixas de ordem emocional e de carência sociocultural eram utilizadas nestes documentos para justificar o baixo desempenho do aluno e o fracasso escolar, corroborando com práticas individualizantes: "Intervir em conteúdos como relacionamento interpessoal, timidez, agressividade, socialização e outros; orientar os pais quanto às dificuldades e avanços da criança e adolescente e realizar diagnósticos" (FEDF, 1992, p.05).

A atuação do psicólogo escolar no modelo clínico tem sido problematizada pela Psicologia Escolar contemporânea por se coadunar com práticas individualizantes que desconsideram a complexidade do processo educativo e seus atores, além de 
contribuírem com mecanismos de exclusão de estudantes, principalmente aqueles que apresentam problemas de aprendizagem (Marinho- Araujo, 2014; Martinez, 2009). A segunda edição da OP ${ }^{\circ} 20$ (FEDF, 1994b) avançou e propôs a presença do psicólogo no contexto escolar, desenvolvendo ações preventivas. Esse documento foi um desdobramento da pesquisa de Araujo (2003) acerca da definição da especificidade da atuação do psicólogo escolar e do desenvolvimento de competências para consolidação de identidade desse profissional (Marinho-Araujo \& Almeida, 2005). Nessa perspectiva, essa normatização propõe:

\begin{abstract}
Operacionalizar ações dentro de uma ótica interdisciplinar; participar do levantamento das possíveis causas de evasão, repetência, problemas institucionais e disciplinares; participar da análise do currículo da escola; conscientizar professores quanto à importância dos objetivos do domínio afetivo no processo ensino-aprendizagem; participar dos conselhos de classe; acompanhar e avaliar ações desenvolvidas (FEDF,1994, pp. 15-16).
\end{abstract}

Para Araujo \& Almeida (2003), por ser um contexto complexo e multideterminado, a escola se configura como um lócus privilegiado de interações e um espaço de antagonismos e transformações que possibilitam a imersão do psicólogo nesse contexto. A atuação desse profissional requer um olhar crítico sobre o processo educativo e as relações, identificando mecanismos de exclusão e promovendo a conscientização dos atores educativos sobre concepções cristalizadas que orientam as práticas pedagógicas (Marinho-Araújo, 2014; Petroni, 2013; Petroni \& Trevisan de Souza, 2014).

A OP n 22 (FEDF, 1994a) e a OP/2006 (GDF/SEDF, 2006) se destacam por evidenciarem a participação do psicólogo escolar na implantação de políticas públicas, como é o caso da Inclusão Escolar (Fleith, 2009; Martinez, 2007). A ação intencional do psicólogo escolar é importante para promover reflexões críticas sobre o impacto de tais políticas no contexto escolar, sem limitar-se aos indivíduos, mas considerando os processos subjetivos da escola como espaço social (Martinez, 2007). O psicólogo escolar deve assumir o compromisso profissional de refletir, discutir e contribuir para elaboração de políticas públicas educacionais menos excludentes, bem como identificar as barreiras administrativas, burocráticas, sociais, culturais e pedagógicos para efetivação dessas políticas (Fleith, 2009; Martinez, 2007).

A OP/2010 (GDF/SEDF, 2010) propõe a atuação do psicólogo escolar nas seguintes dimensões: Mapeamento Institucional (MI), Assessoria ao trabalho coletivo e Acompanhamento ao processo de ensino e aprendizagem. Essas dimensões foram baseadas na pesquisa de Araujo (2003) e atualizadas em Marinho-Araujo (2014). O MI integra a atuação preventiva e institucional promovendo o conhecimento do contexto 
escolar, de aspectos sociais, políticos e ideológicos presentes nas concepções de desenvolvimento e de aprendizagem que orientam o processo educativo e propõe estratégias metodológicas que permitem ao psicólogo escolar ter uma visão profunda da instituição escolar e atuar de forma intencional, sistematizada e adequada, tais como:

\begin{abstract}
Análise de dados estatísticos relacionados ao rendimento escolar (aprovação, evasões, transferência); análise de documentos (legislações, proposta pedagógica, matrizes curriculares, regimento interno, estratégia de matrículas, projetos educacionais e outros); entrevistas com direção, coordenadores para conhecer a atuação desses profissionais; entrevistas individuais com professores para conhecer concepções de ensino; aprendizagem, avaliação, motivações para o trabalho docente e percepção do contexto; observação dos espaços e as dinâmicas pedagógicas: sala de aula, recreio, reuniões de coordenação e outras; levantamento de informações históricas acerca da instituição e conjuntura social, política e econômica na qual a instituição educacional se insere (GDF/SEDF, 2010, pp. 94-95).
\end{abstract}

Ressalta-se que no Mapeamento Institucional não deve ser considerado um levantamento de informações sociodemográficas, mas um estudo de conjuntura que analisa os aspectos históricos, políticos, econômicos, sociais e pedagógicos presentes no contexto escolar. Essas informações poderão orientar a atuação do psicólogo escolar em ações avaliativas e interventivas que promovam espaços de interlocução, a ressignificação da concepção de fracasso por meio da valorização e disseminação de práticas exitosas e consolidação de uma cultura do sucesso escolar (Marinho-Araujo, 2014).

Na dimensão da OP/2010 (GDF/SEDF) relativa ao Assessoramento ao Trabalho Coletivo, o psicólogo escolar pode propiciar a construção de espaços democráticos de interlocuções acerca de concepções de desenvolvimento e aprendizagem que orientam as práticas pedagógicas e a construção do projeto político pedagógico. Essa dimensão favorece ações intencionais a partir da integração dos atores educativos em prol de objetivos comuns (Martinez, 2010) e contribui para a consolidação do espaço coletivo como lócus de mediação de subjetividade e desenvolvimento humano adulto.

Ao apresentar a dimensão do Acompanhamento do Processo de Ensino e Aprendizagem, a OP/2010 (GDF/SEDF, 2010) orienta que a atuação do psicólogo escolar deve "voltar-se para análise e intervenção na relação professor, aluno e objeto de conhecimento" (Marinho-Araujo, 2014, p.170), visando compreender a queixa a partir do professor que a encaminhou, investigando como ela foi construída. Essa dimensão não se restringe ao atendimento ao aluno, mas envolve ações planejadas e 
intencionais, individuais e coletivas para o enfrentamento da queixa escolar, tais como:

Observação da dinâmica de sala de aula e dos demais contextos educativos; análise, em parceria com o professor e outros profissionais da instituição, da produção dos alunos; discussão das concepções de ensino e de aprendizagem dos professores e seus impactos no planejamento das atividades escolares (GDF/SEDF, 2010, pp. 98-99).

O Acompanhamento do Processo de Ensino e Aprendizagem deve promover "a ressignificação de práticas pedagógicas e dos papeis e responsabilidades dos atores educativos" (Marinho- Araujo, 2014, p. 162). O trabalho nessa dimensão, em articulação com as ações do Mapeamento Institucional e da Assessoria ao Trabalho Coletivo, possibilita um conhecimento amplo dos aspectos interescolares, intersubjetivos, socioeconômicos, ideológicos presentes no contexto escolar. Portanto, as três dimensões apresentadas na OP/2010 (GDF/SEDF, 2010) representam possibilidades de uma atuação em Psicologia Escolar comprometida com o desenvolvimento de todos e a melhoria na qualidade da educação na rede pública de ensino do Distrito Federal.

\section{Considerações finais}

A análise das Orientações Pedagógicas mostrou uma articulação historicamente consolidada da Psicologia com a Educação para o atendimento dos estudantes da rede pública de ensino do Distrito Federal. Essas diretrizes acompanharam as discussões nacionais e locais na área da Psicologia e promoveram avanços teóricometodológicos na Psicologia Escolar da SEDF. As produções acadêmicas (Araujo, 2003; Neves, 2001) empreendidas pelo Laboratório de Psicologia Escolar na Universidade de Brasília foram basilares na elaboração das Orientações Pedagógicas examinadas e promoveram transformações nas práticas dos psicólogos escolares, principalmente na transição da atuação no modelo clínico, centrada no aluno, para a atuação institucional envolvendo todos os atores educativos.

As primeiras Orientações Pedagógicas, $n^{\circ} 20$ (FEDF, 1992,1994b) e $n^{\circ} 22$ (FEDF, 1994a) contribuíram para organizar e orientar a atuação do psicólogo escolar e para os avanços teóricos e metodológicos que levaram à construção dos documentos posteriores. São evidentes os avanços quanto à ampliação do público-alvo e modalidades de ensino atendidas, principalmente após a regulamentação da Psicologia Escolar na SEDF e a elaboração da OP/2010 (GDF/SEDF, 2010), que sinaliza a importância da universalização desse serviço em modalidades emergentes como o 
ensino fundamental (anos finais), o ensino médio e a educação de jovens e adultos (GDF, 2014).

As Orientações Pedagógicas da Psicologia Escolar na SEDF promoveram significativos avanços na ressignificação de concepções e práticas dos psicólogos escolares na rede pública de ensino. A OP/2010 (GDF/SE-DF, 2010) se destaca por romper com paradigmas tradicionais, evidenciando a interdependência de fatores biológicos e sociais no processo educativo e o desenvolvimento humano como um processo histórico influenciado por aspectos sociais, culturais,relacionais e pela proposta de atuação institucional que considera as singularidades dos sujeitos e do contexto educativo. Essa diretriz configura-se como um importante recurso para a atuação crítica, consciente e transformadora do psicólogo escolar na SEDF.

\section{Referências}

ANTUNES, Mitsuko Aparecida Makino. Psicologia Escolar e Educacional: história, compromissos e perspectivas. Psicologia Escolar e Educacional, 12 (2), 469-475, Julho-Dezembro. 2008.

ARAUJO, ClaisyMaria Marinho. Psicologia Escolar e o desenvolvimento de competências: Uma opção para capacitação continuada. 2003(334fls). Tese (Doutorado em Psicologia) - Programa de Pós-graduação em Desenvolvimento Humano e Saúde. Universidade de Brasília, 2003.

BOCK, A. M. B. A psicologia a caminho do novo século: Identidade profissional e compromisso social. Estudos de Psicologia, 4, 315-329, Novembro. 1999.

Barbosa, Rejane Maria. Psicologia Escolar nas Equipes de Atendimento/Apoio à Aprendizagem de Samambaia: A atuação Institucional a partir da Abordagem por competências. 2008 (187 fls). Dissertação (Mestrado em Psicologia) - Programa de Pós-graduação em Desenvolvimento Humano e Saúde. Universidade de Brasília, 2008.

CAVALCANTE, Lorena. Almeida, \& AQUINO, Fabíola de Sousa. Braz. Ações de psicólogos escolares de João Pessoa sobre queixas escolares. Psicologia em Estudo, 18(2), 353-362, Abril-Junho. 2013. 
COLLARES, Cecília Azevedo Lima \& MOYSÉS, Maria Aparecida Afonso. Preconceitos no cotidiano escolar: Ensino e medicalização. São Paulo: Cortez, 1996.

CORREIA, M., \& CAMPOS, Herculano. Ricardo. Psicologia Escolar: Histórias, tendências e possibilidades. In YAMAMOTO, Oswaldo e NETO, Cabral (Orgs.), O psicólogo e a escola: uma introdução ao estudo da Psicologia Escolar (pp. 137185). Natal, RN: EDUFRN, 2004.

FACCI, Marilda. Gonçalves. Dias, \& SOUZA, Marilene. Proença. Rabelo. " - O Que Este Menino Tem?": Contribuições do método instrumental de Vigotski para o processo de avaliação psicológica. In MARINHO-ARAUJO, Claisy Maria \& GUZZO, Raquel Souza Lobo (Orgs.), Psicologia Escolar: Identificando e superando barreiras. Campinas: Editora Alínea, 2011. (pp. 77-100).

FLEITH, Denise. Souza.AContribuição do Psicólogo Escolarpara o Desenvolvimento das Altas Habilidades. In MARINHO-ARAUJO, Claisy Maria(Org), Psicologia Escolar: Novos cenários e Contextos de Pesquisa, Formação e Prática. Campinas: Alínea, 2009.(pp. 245-264).

FUNDAÇÃO EDUCACIONAL DO DISTRITO FEDERAL / Departamento de Pedagogia. Orientação Pedagógica n²2 - Atendimento diagnóstico e avaliação psicopedagógica. Brasília: FEDF, 1994a.

FUNDAÇÃO EDUCACIONAL DO DISTRITO FEDERAL /Departamento de Pedagogia, Orientação Pedagógica n²0 - Atendimento psicopedagógico. Brasília: FEDF, 1994b.

FUNDAÇÃO EDUCACIONAL DO DISTRITO FEDERAL /Departamento de Pedagogia, Orientação Pedagógica n²0 - Atendimento psicopedagógico. Brasília: FEDF, 1992.

GOVERNO DO DISTRITO FEDERAL. Orientação pedagógica: Equipe Especializada de Apoio à Aprendizagem. Brasília: Secretaria de Estado de Educação do Distrito Federal, 2010.

GOVERNO DO DISTRITO FEDERAL. Orientação pedagógica: Equipes de Atendimento/Apoio à Aprendizagem. Brasília: Secretaria de Estado de Educação do Distrito Federal, 2006.

GOVERNO DO DISTRITO FEDERAL. Relatório de Gestão e Políticas Públicas 2011-2014. Brasília: Secretaria de Estado de Educação do Distrito Federal, 2014.

GUZZO, Raquel Souza Lobo\& MEZZALIRA, A. S. C. (2011). 2008 - Ano da 
educação para os psicólogos: Encaminhamentos e próximos passos. In MARINHOARAUJO, Claisy Maria \& GUZZO, Raquel Souza Lobo (Orgs.), Psicologia Escolar: Identificando e superando barreiras Campinas: Editora Alínea. (pp. 11-31).

GUZZO, Raquel Souza Lobo. Escola amordaçada - compromisso do psicólogo com esse contexto. In: MARTINEZ, Albertina. Mitjáns (Org.). Psicologia escolar e compromisso social. Campinas: Alínea, 2007.(pp. 17-29).

MADUREIRA, Ana Flavia Amaral \& BRANCO, Ângela. Uchoa. A pesquisa qualitativa em psicologia do desenvolvimento: questões epistemológicas e implicações metodológicas. Temas em Psicologia da SBP, 9, 63-75, 2001.

MARINHO- ARAÚJO, Claisy. Maria. \& NEVES, Marisa. Maria. Brito da Justa. Psicologia escolar: perspectivas e compromissos na formação continuada. In CAMPOS, Herculano Ricardo (Org), Formação em Psicologia Escolar: Realidades e Perspectivas. Campinas: Alínea, 2007.(pp. 69-87).

MARINHO-ARAUJO, Claisy. Maria. Psicologia Escolar: Pesquisa e intervenção. Em Aberto, 23, 15-35, Março. 2010.

MARINHO-ARAUJO, Claisy. Maria. Intervenção Institucional: Ampliação crítica e política da atuação em Psicologia Escolar. Em R. S. L. Guzzo (Org.), Psicologia Escolar: Desafios e Bastidores na Educação Pública (pp. 153-175). Campinas: Editora Alínea, 2014.

MARINHO-ARAUJO, Claisy. Maria \& Almeida, Sandra. Francesca Conte. Psicologia Escolar: Construção e consolidação da identidade profissional. Campinas: Alínea, 2005

MARINHO-ARAUJO, Claisyet al. Psicologia Escolar no Distrito Federal: História e compromisso com políticas públicas. In MARINHO-ARAUJO, Claisy Maria \& GUZZO, Raquel Souza Lobo (Orgs.): Identificando e superando barreiras. Campinas: Editora Alínea, 2011.(pp. 47-76).

MARTíN-BARÓ, Ignácio. O papel do psicólogo. Estudos de Psicologia (Natal), 2, 7-27, 1996.

MARTÍN-BARÓ, Ignácio. Por uma Psicologia da Libertação. InGUZZO, Raquel Souza Lobo\& F. Lacerda Jr. (Orgs.). Psicologia social para a América Latina: o resgate da Psicologia da Libertação (pp. 181-197). Campinas: Alínea, 2011.

MARTÍNEZ, Alberina. Mitjáns. O psicólogo na construção da proposta pedagógica da escola: Áreas de atuação e desafios para a formação. In ALMEIDA, Sandra Francesca Conte (Org.). Psicologia Escolar: Ética e competências na formação e 
atuação profissional Campinas: Editora Alínea, 2003. (pp. 105-124).

MARTíNEZ, Albertina. Mitjáns. O psicólogo escolar e os processos de implantação de políticas públicas: Atuação e formação. In CAMPOS, Herculano Ricardo(Org.). Formação em psicologia escolar: Realidades e perspectivas (pp. 109-134). Campinas: Editora Alínea, 2007.(pp. 109-134).

MARTíNEZ, Albertina Mitjáns. Psicologia Escolar e Educacional: Compromissos com a educação brasileira. Psicologia Escolar e Educacional, 13(1), 169-177, Janeiro-Junho. 2009.

MARTíNEZ, Albertina. Mitjáns. O que pode fazer o psicólogo na escola? Em Aberto, 23(83), 39-56, Março. 2010.

MINISTÉRIO DA SAÚDE. Conselho Nacional de Saúde. Disponível em http:// bvsms.saude.gov.br/bvs/saudelegis/cns/2013/res0466_12_12_2012.html (Acesso em 02/09/15).

NEVES, Marisa. Maria. Brito. Justa. Queixas escolares: Conceituação, discussão e modelo de atuação. In MARINHO-ARAUJO, Claisy Maria \& GUZZO, Raquel Souza Lobo (Orgs.): Psicologia Escolar: Identificando e superando barreiras. São Paulo: Alínea, 2011.(pp. 175-192).

NEVES, Marisa. Maria. Brito. Justa\& Almeida, Sandra. Francesca Conte. A atuação da Psicologia Escolar no atendimento aos alunos encaminhados com queixas escolares. InALMEIDA, Sandra Francesca Conte (Org.). Psicologia Escolar: Compromisso ético e competências na formação e atuação profissional (pp. 83104). Campinas: Editora Alínea, 2003.

NEVES, Marisa. Maria. Brito. Justa. A atuação da psicologia nas equipes de atendimento psicopedagógico da rede pública de ensino do Distrito Federal. Tese de Doutorado. Universidade de Brasília, 2001.

PATTO, Maria. Helena Souza. Introdução à Psicologia Escolar. São Paulo: T. A. Queiroz, 1981.

PATTO, Maria. Helena Souza. Psicologia e Ideologia: Uma introdução crítica à Psicologia Escolar. São Paulo: T.A. Queiroz, 1984.

PATTO, Maria. Helena Souza. A produção do fracasso escolar: Histórias de submissão e rebeldia. São Paulo: T. A. Queiroz, 1990.

PENNA-MOREIRA, Paula Cristina Bastos. A Psicologia Escolar nas Equipes de Atendimento/Apoio à Aprendizagem da Secretaria de Estado de Educação do Distrito Federal. 2007 (212 fls). Dissertação (Mestrado em Psicologia) - Programa 
de Pós-graduação em Desenvolvimento Humano e Saúde. Universidade de Brasília, 2007.

PETRONI, Ana. Paula. (2013). Psicologia Escolar e Arte: Possibilidades e limites da atuação do psicólogo na ampliação da promoção da consciência de gestores (Tese de Doutorado não publicada). Pontifícia Universidade de Campinas, Campinas.

PETRONI, Ana. Paula. \& TREVISAN de Souza, Vera. Lúcia. (2014). Psicólogo Escolar e Equipe Gestora: Tensões e Contradições de Uma Parceria Psicologia. Ciência e Profissão, 34 (1), Dezembro. 444-459.

REY, Fernando González. Ideias e Modelos Teóricos na Pesquisa ConstrutivoInterpretativa. In MARTINEZ, Albertina; NEUBERN, Maurício e MORI, Valéria (2014). Subjetividade Contemporânea: discussões epistemológicas e metodológicas. Campinas: Ed. Alínea, 2014.(pp. 13-34).

SECRETARIA DE ESTADO DESAÚDE DO DISTRITO FEDERAL. Centro de Orientação Médico Psicopedagógica (COMPP). Disponível em http://www.saude. df.gov.br/sobre-a-secretaria/hospitais-e-regionais/506-centro-de-orientacaomedico-psicopedagogica-compp.html(acesso em 18/08/15).

SENNA, Sylvia Regina Carmo Magalhães\& Almeida, Sandra Francesca. Conte. (2005). Formação e atuação do psicólogo escolar da rede pública de ensino do Distrito Federal. In MARTINEZ, Albertina, Mitjáns (Org.), Psicologia Escolar e compromisso social: Novos discursos, novas práticas. Campinas: Alínea.(pp.199230).

SEVERINO, Antonio Joaquim. Metodologia do Trabalho científico. São Paulo. Cortez, 2007.

VYGOTSKY, Lev Semenovitch. Psicologia Pedagógica. São Paulo: Martins Fontes (Texto original publicado em 1926), 2004.

VYGOTSKY, Lev Semenovitch. A formação social da mente. São Paulo: Martins Fontes. (Textos originais publicados 1984), 2007. 
Recebido em 03 de setembro de 2015

Aprovado em 16 de dezembro de 2016

Liliene Alves Veloso da Silva possuigraduação em Pedagogia, Psicologia e Pós-Graduada em Desenvolvimento Humano e Educação Inclusiva- Unb (2011). Atualmente, é mestranda do Programa de pós-graduação em Processos de Desenvolvimento Humano e Saúde do Instituto de Psicologia da Universidade de Brasília- PGPDS/Unb. Email: lilieneaveloso@gmail.com

Claisy Maria Marinho-Araujo é Doutora em Psicologia e Professora Adjunta da Universidade de Brasília, Instituto de Psicologia. Email: claisy@unb.br 